\title{
Social and Psychological Impact of Traumatic Dental Injuries in Children and Adolescents: A Review of Literature
}

\author{
Kumar $\mathbf{S}^{1}$, Neha ${ }^{2}$, Kaur $\mathbf{G}^{3}$, Kashyap $\mathrm{N}^{4 *}$, Palak ${ }^{\mathbf{1}}$ and Radhe $\mathbf{A}^{\mathbf{1}}$ \\ ${ }^{1}$ Postgraduate student (MDS), Department of Pedodontics and Preventive Dentistry, Maharaja Ganga Singh Dental College and Research \\ Centre, India
}

${ }^{2}$ Reader, Department of Pedodontics and Preventive Dentistry, Maharaja Ganga Singh Dental College and Research Centre, India

${ }^{3}$ MDS, Department of Pedodontics and Preventive Dentistry, Maharaja Ganga Singh Dental College and Research Centre, India

${ }^{4}$ HOD, Department of Pedodontics and Preventive Dentistry, Maharaja Ganga Singh Dental College and Research Centre, India

*Corresponding author: Kashyap N, Department of Pedodontics and Preventive Dentistry, Maharaja Ganga Singh Dental College and

Research Centre, Rajasthan, India

\begin{abstract}
Traumatic dental injuries in childhood are quite commonplace, with a reported occurrence of up to $30 \%$ globally. The effect of traumatic dental injuries can have adverse effects on the child, his family and the dentist treating the child. This is an area which has always been neglected. The psychological effect of TDIs are individual for each patient and as such should be treated as a whole. Children who had suffered a traumatic dental injury seems to have the worse oral health related quality of life and they are more likely to have low self-esteem when their dental injuries are not properly treated. Children who have dental anomalies are judged poorly by their peers and the society as a whole and these judgements are increased many folds due to the presence of social media. At present there is a lack of proper research to study the psychological effect of traumatic dental injuries. Currently though there is advancement in the field of managing traumatic dental injuries there is still a lack of awareness regarding the young patient's experience and values.
\end{abstract}

Keywords: Traumatic dental injuries; psychological; children

\section{Introduction}

Facial esthetics play an important role in self-identification, selfimage, self-presentation, and interpersonal confidence. The face is an important part of human development and facial expression is the most important element in non-verbal communication. The significance of the teeth in a smile should not be underestimated. Psychologists define a traumatic experience as an intense and sudden event that overwhelms the person's capacity to cope with the memories and feelings that are triggered by it. Such traumatic experiences may lead to psychological symptoms, such as depression and anxiety [1]. The psychological effect of TDIs are individual for each patient and as such should be treated as a whole.

\section{Stages of Psychological Development}

\section{Toddlers}

Toddlers aged about 1.5 to 3 years are developing a sense of doing things on their own. The child has a very strong drive to investigate the boundaries set by adults to try out his or her own power and abilities, and to experience new, thrilling situations [2]. A traumatic experience such as intense pain puts limits on the child's expanding world [3]. Furthermore, the experience of pain is imprinted on the mind of young children $[4,5]$.

\section{Later preschool childhood}

During later childhood, aged 3-5 years, children develop a clear concept of themselves as 'me', knowing they are a separate person and no longer dependent on their parents in familiar situations. Development brings the child into a world of magic, oscillating between reality and fantasy. A feeling of guilt may intensify the psychological impact. Furthermore, at this age, children perceive the body as a bag containing feelings, tears, food, a heart, and blood; it is frightening if there is a hole in the bag, so it has to be mended as soon as possible. 


\section{School age}

School age (6-12 years) is a period of life characterized by intense development in social skills and cognitive growth. Around 9 years of age, the child reaches an adult conception of life and death, namely, a full understanding that everyone who lives will also die, including oneself. This leads to a deeper understanding of the transient nature of life and might cause an easily evoked fear of death and illness [6]. Such a fear could be triggered by a TDI event associated with intense pain.

\section{Adolescence}

Adolescence (13-20 years) is the final period of the child's development into adulthood. Intellectually, the young person is capable of formal operations [7]. Thus, an adolescent has adult intellectual concepts, but less experience than an adult. Teenagers often experience mood swings, as they are trying to achieve a stable inner identity and self-esteem. This is a process that goes on for years and takes great energy. Emotionally, the teenager will pass through different periods, the first of which is dominated by regression, as the wish to remain an innocent child clashes with the need to grow up. The last period also represents the final emotional separation from parents and the security of childhood, in which there is loss and often some degree of depression until the young person finds a new sense of belonging [8]. A traumatic experience with intense pain during this period of development may exaggerate any expression of regression, aggression, or depression.

\section{Psychosocial Aspects of Traumatic Dental Injuries}

The aspect of oral conditions on an individual's physical and psychosocial wellbeing can be assessed through subjective indicators called Oral Health Related Quality of Life (OHRQoL) measures. The aim is to assess major changes in behavior that upset social function and consequently alter people's quality of life [9]. Studies on oral health and quality of life should address four areas:

a) Pain and discomfort.

b) Functional aspects related to the ability to chew and swallow food without difficulty and speak and pronounce words correctly.

c) Psychological aspects related to physical appearance and self-esteem; and

d) Social aspects reflecting social interaction and communication with people $[10,11]$.

These dimensions were described by Locker [12], based on The International Classification of Functioning, Disability and Health developed by the World Health Organization (WHO) [13]. According to Locker [12], mouth injuries and diseases cause damage that can directly lead to disabilities or indicate the following symptoms: pain and discomfort, functional limitation, and dissatisfaction with one's own appearance. These symptoms can trigger physical, psychological, or social limitations, and consequently, disability. In turn, pain and discomfort can lead straight to disability. Oral health problems have been increasingly recognized as having an important negative impact on quality of life for individuals and populations. Traumatic dental injuries occur most commonly in the anterior sextants of the dental arches [14]. The psychosocial problem may occur due to the incident that caused the TDI or because of esthetic impairment by a broken or blackened tooth [15], an increase in dentin sensitivity attributed to the exposure by fracture [16] or another functional problem [15]. The magnitude of the psychological impact depends on the type of event or associated violence. For example, when TDI is the result of aggression, physical assault or abuse, the potential to generate psychological stress is much higher than when resulting from sports activities or an accidental fall. These conditions can cause serious esthetic, psychological and social damage, besides producing significant costs for the TDI victim and their family [17].

\section{Ways to Explore the Impact of Traumatic Dental Injury \\ Quantitative way}

To date, our knowledge of TDI impacts in children has been largely based on findings from quantitative research. Oral health related quality of life (OHRQoL) questionnaires have been used by researchers which have been validated for different age groups as well as in different languages [18-22].These questionnaires have been designed to measure the impact of dental anomalies or injuries on the child's everyday life [22,23]. To calculate a total OHRQoL Score children are asked about the number of impacts that they had in the past three months on their daily life. Questions belonging to different fields of life are generally asked such as social life, wellbeing, oral symptoms, and physiological functions.

\section{Qualitative way}

The first documented case of the impact of a traumatic dental injury on social life was published 60 years ago [24]. It documented the case of a 9-year-old boy who was an active member of two choirs. The boy had an injury in which he suffered from uncomplicated fracture of four permanent incisors. Due to this the boy developed a lisp. The boy was removed from his position in the choirs and as a result the boy suffered from mood swings and sleep disturbances. The similarity of the psychosocial impact the boy had to the theoretical model of OHRQoL was striking $[25,26]$.

\section{Concern regarding appearance}

Youths today are more concerned with their appearance. They are more concerned about following the norms setup by society. They are also concerned about the judgement of their peers and society as a whole. These judgements can have lifelong impact on their social life, career, and judicial outcomes [27-29]. Children who have suffered from dental anomalies as a result of TDIs have low 
self-esteem and are prone to bullying in schools. They are worried about the unkind comments that are thrown at them by society [30]. Hence it is the responsibility of the dentist to be sympathetic and provide timely treatment according to the child's social standing.

\section{Psychological effects of TDI}

The nature and the circumstances of TDI can lead to mental health problems in children. A study in the UK showed that one in six children suffer from post-traumatic stress disorder up to eight months after the injury [31]. Hence it is necessary for pediatric teams responding to dental emergencies to properly assess the children psychologically after a TDI and put them under proper care for their emotional support [32].

\section{TDI, its treatment and its effect}

The treatment of TDI has a psychological consequence of its own on the concerned children and their families. When the TDIs are complex the concerned treatments are prolonged, and this places high demands on the concerned children and their families. Studies in the UK, Canada and USA have shown these [33-36]. In a study in Toronto which tried to find out the impact of avulsion injuries on the children and their families, it was found that the children had to visit hospitals nine times in a year on an average. They received over seven hours of dental treatment and lost two weeks of schooling at an average [33].It is also necessary to follow the long term consequences and prognosis of the teeth treated after a TDI throughout adolescence and early adulthood [37].

\section{Economic consequences}

The patient should be informed about means of reducing a possible economic impact of the TDI (i.e. support from public or insurance companies). knowledge and skills to make an accurate diagnosis and perform appropriate and prompt emergency treatment. Lack of postoperative information might add to emotional stress during emergency treatment as the child anticipates future problems. Give information in as concise and positive a manner as possible, emphasizing the likelihood of recovery and also give written information. Pain adds significantly to both physiologic and psychological stress. This means that immediate and skillful pain control should be given very early at the emergency ward or if possible, at the place of injury. Post traumatic follow up gives an excellent opportunity to talk the whole treatment through, from the moment of the injury until the expected end result. This will reduce negative feelings about dental care.

\section{Conclusion}

There are many implications of TDIs. They may be social or psychological. In most cultures, the face is regarded as the most precious characteristic of human identity. A smile is an essential feature both for children and adults. A traumatic dental injury may affect the appearance due to a fracture, discoloration of teeth or avulsion of teeth. The trauma event in itself might have serious psychological effects. Keep in mind that even the youngest child will remember. Negative effects could be reduced by means of good emergency care. The dental team must be aware of and understand the anxiety of both children and parents. Awaiting treatment is a stressful experience for children, especially if they are also exposed to the frightening sight of other emergency patients and are in unfriendly surroundings. Even with recent advancement in the management of TDIs to improve dental wellbeing there is lack of awareness about the psychological and economical implication of TDIs.

\section{References}

1. Pine DS, Cohen JA (2002) Trauma in children and adolescents: risk and treatment of psychiatric sequelae. Biol Psych 51(7): 519-531.

2. Fraiberg S (1959) The magic years. Charles Scriber's Sons, New York. USA.

3. Koch G, Poulsen S (2001) Pediatric dentistry: a clinical approach Munksgaard, Copenhagen, USA.

4. Schechter D, Berde C, Yaster M (2002) Pediatric dentistry. Baltimore: Lippincott Williams \& Wilkins.

5. Bush A, Harkins S (1991) Children in pain: clinical and research issues from developmental perspective. Springer Verlag, New York, USA.

6. Lagerheim B (1983) "Why me?" A depressive crisis at the age of nine in handicapped children. In: Gyllensvärd Å, Laurén K, eds. Psychomatic diseases in childhood. Sven Jerring Foundation, Stockholm, Sweden.

7. Piaget J (1959) The language and thought of the child. Routledge \& Kegan Paul, London, UK.

8. Kaplan L (1984) Adolescence: the farewell to childhood. Simon \& Schuster, New York, USA.

9. Cushing AM, Sheiham A, Maizels J (1986) Developing socio-dental indicators - the social impact of dental disease. Comm Dent Health 3: 3-17.

10. Locker D, Allen F (2007) What do measures of 'oral health related quality of life' measure? Comm Dent Oral Epidemiol 35: 401-411.

11. Allison PJ, Locker D, Feine JS (1997) Quality of life: a dynamic construct. Soc Sci Med 45(2): 221-230.

12. Locker D (1988) Measuring oral health: a conceptual framework. Comm Dent Health 5(1): 3-18.

13. (2018) World Health Organization International classification of functioning, disability and health (ICF).

14. Traebert J, Almeida IC, Marcenes W (2003) Etiology of traumatic dental injuries in 11 to 13-year-old schoolchildren. Oral Health Prev Dent 1(4): 317-323.

15. Traebert J, Lacerda JT, Foster Page LA, Thomson WM, Bortoluzzi MC (2012) Impact of traumatic dental injuries on the quality of life of schoolchildren. Dent Traumatol 28(6): 423-428.

16. Traebert J ML, Traebert ESA, Bortoluzzi MC (2014) Dental hot-cold sensitivity and traumatic dental injuries. J Res Dent 2: 111-118.

17. Antunes LA, Leao AT, Maia LC (2012) The impact of dental trauma on quality of life of children and adolescents: a critical review and measurement instruments. Cien Saude Colet 017: 3417-3424.

18. Borges TS, Vargas Ferreira F, Kramer PF, Feldens CA (2017) Impact of traumatic dental injuries on oral health-related quality of life of preschool children: A systematic review and meta-analysis. PLoS ONE 12(2): e0172235 
19. Marshman Z, Gupta E, Baker SR, Robinson PG, Owens J, et al. (2015) Seen and heard: Towards child participation in dental research. Int J Paediatr Dent 25(5): 375-382.

20. Wallace A, Rogers HJ, Zaitoun H, Rodd HD, Gilchrist F, et al. (2016) Traumatic dental injury research: On children or with children? Dent. Traumatol 33(3): 153-159.

21. Gilchrist F, Rodd HD, Deery C, Marshman Z (2013) Involving children in research, audit, and service evaluation. Br Dent J 214(11): 577-582.

22. Zaror C, Martínez Zapata MJ, Abarca J, Díaz J, Pardo Y, et al. (2017) Impact of traumatic dental injuries on quality of life in preschoolers and schoolchildren: A systematic review and meta-analysis. Commun Dent Oral Epidemiol 46(1): 88-101.

23. Gilchrist F, Rodd H, Deery C, Marshman Z (2014) Assessment of the quality of measures of child oral health-related quality of life. BMC Oral Health 14: 40 .

24. Slack GL, Jones JM (1955) Psychological effect of fractured incisors. Br Dent J 6: 368-388.

25. Locker DI (2004) Oral health and quality of life. Oral Health Prev Dent 2(Suppl 1): 247-253.

26. Genderson MW, Sischo L, Markowitz K, Fine D, Broder HL (2013) An Overview of Children's Oral Health-Related Quality of Life Assessment: From Scale Development to Measuring Outcomes. Caries Res 47: 13-21.

27. Karunakaran T, Gilbert D, Asimakopoulou K, Newton T, Newton JT (2011) The influence of visible dental caries on social judgements and overall facial attractiveness amongst undergraduates. J Dent 39(3): 212217.

28. Stolier RM, Hehman E, Keller MD, Walker M, Freeman JB (2018) The conceptual structure of face impressions. Proc Natl Acad Sci USA 115(37): 9210-9215.
29. Wilson JP, Rule NO (2015) Facial Trustworthiness Predicts Extreme Criminal-Sentencing Outcomes. Psychol Sci 26(8): 1325-1331.

30. Seehra J, Newton JT, Di Biase AT (2011) Bullying in schoolchildren-its relationship to dental appearance and psychosocial implications: An update for GDPs. Br Dent J 210(9): 411-415.

31. Stallard P, Velleman R, Langsford J, Baldwin S (2001) Coping and psychological distress in children involved in road traffic accidents. Br J Clin Psychol 40(2): 197-208.

32. Odenbach J, Newton A, Gokiert R, Falconer C, Courchesne C, et al. (2014) Screening for post-traumatic stress disorder after injury in the pediatric emergency department-a systematic review protocol. Syst Rev 3: 19.

33. Nguyen PMT, Nguyen PT, Kenny DJ, Barrett EJ (2004) Socio-economic burden of permanent incisor replantation on children and parents. Dent Traumatol 20(3): 123-133.

34. Berger TD, Kenny DJ, Casas MJ, Barrett EJ, Lawrence HP (2009) Effects of severe dentoalveolar trauma on the quality-of-life of children and parents. Dent Traumatol 25(5): 462-469.

35. Porritt JM, Rodd HD, Baker SR (2012) Parental quality-of-life impacts following children's dento-alveolar trauma. Dent Traumatol 29(2): $92-$ 98.

36. Lee JY, Divaris K (2009) Hidden consequences of dental trauma: The social and psychological effects. Pediatr Dent 31(2): 96-101.

37. Robertson A, Norén J (1997) Subjective Aspects of Patients with Traumatized Teeth A 15-Year Follow-Up Study. Acta Odontol Scand 55(3): 142-147.

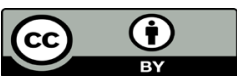

This work is licensed under Creative Commons Attribution 4.0 License

To Submit Your Article Click Here: Submit Article

DOI: $10.32474 /$ IPDOAJ.2020.04.000188

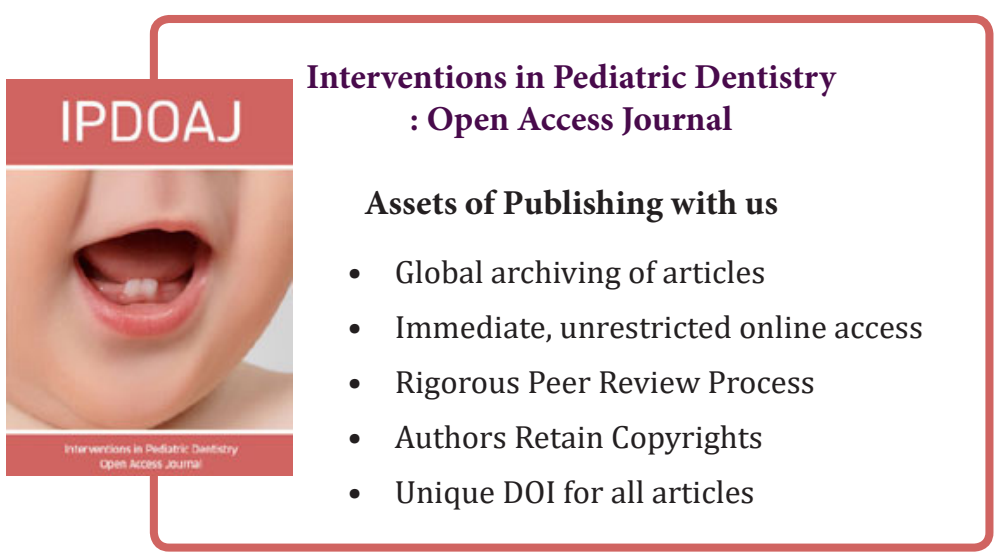

